\author{
В. С. Безбородов
}

Белорусский государственный технологический университет

\title{
РЕТРОСПЕКТИВА РАЗВИТИЯ ХИМИИ ЖИДКОКРИСТАЛЛИЧЕСКИХ И АНИЗОТРОПНЫХ МАТЕРИАЛОВ В БЕЛАРУСИ
}

Ретроспектива развития химии жидкокристаллических и анизотропных материалов в Беларуси обсуждена и рассмотрена на примерах подходов к синтезу, разработанных в последние десятилетия. Показано, что анизотропные и жидкокристаллические соединения могут быть получены с использованием различных превращений соответствующих 3,6-дизамещенных циклогекс-2енонов, транс-2,5-дизамещенных циклогексанонов, 5-замещенных циклогексан-1,3-дионов, 3,5-дизамещенных 2-изоксазолинов, 1,2-дизамещенных циклопропанолов и непредельных эпоксикетонов.

Ключевые слова: жидкие кристаллы, анизотропные соединения, полупродукты получения жидких кристаллов и анизотропных соединений.

Для цитирования: Безбородов В. С. Ретроспектива развития химии жидкокристаллических и анизотропных материалов в Беларуси // Труды БГТУ. Сер. 2, Химические технологии, биотехнологии, геоэкология. 2021. № 1 (241). С. 186-196.

\section{V.S. Bezborodov \\ Belarusian State Technological University}

\section{RETROSPECTIVE OF DEVELOPMENT OF LIQUID CRYSTAL AND ANISOTROPIC MATERIALS CHEMISTRY IN BELARUS}

A retrospective of the development of liquid-crystalline and anisotropic materials chemistry in Belarus is discussed and considered using examples of synthetic approaches developed in recent decades. It was shown that anisotropic and liquid-crystalline compounds can be obtained using various transformations of the corresponding 3,6-disubstituted cyclohex-2-enones, trans-2,5-disubstituted cyclohexanones, 5-substituted cyclohexane1,3-diones, 3,5-disubstituted 2-isoxazolines, 1,2-disubstituted cyclopropanols and unsaturated epoxy ketones.

Key words: liquid crystals; anisotropic compounds, intermediates for liquid crystals and anisotropic compounds

For citation: Bezborodov V. S. Retrospective of development of liquid crystal and anisotropic materials chemistry in Belarus. Proceedings of BSTU, issue 2, Chemical Engineering, Biotechnologies, Geoecology, 2021, no. 1 (241), pp. 186-196 (In Russian)

Введение. Работы по синтезу и исследованию зависимости свойств мезоморфных соединений от их химической структуры до 60-х годов прошлого века носили во многом чисто академический характер. Начиная с 60-х годов, после появления в США патентов (Дж. Фергасон) на применение холестерических жидких кристаллов (ЖК) для визуализации тепловых и СВЧ-полей и в других приложениях, интерес к ЖК резко возрос. Во многих странах мира (США, Япония, ФРГ, ГДР, Англия и др.), включая СССР, стали интенсивно вестись работы по синтезу и исследованию холестерических ЖК. Последующее открытие эффекта динамического рассеяния света в тонких слоях нематического ЖК с отрицательной диэлектрической анизотропией, а также обнаружение эффективной переориентации молекул нематических ЖК с положительной анизотропией под воздействием слабого электрического поля стимулировали рост числа работ и патентов по синтезу, исследованию физических свойств и применению жидких кристаллов. Это привело к тому, что к 1980-м годам сформировался новый специфический раздел органической химии «Химия жидких кристаллов» со своей стратегией синтеза мезоморфных веществ и различных добавок, необходимых для создания эффективных ЖК материалов, и с тщательным анализом связи между структурой молекул мезоморфных соединений и их свойствами, что необходимо для целенаправленного поиска жидких кристаллов, обладающих улучшенными эксплутационными параметрами.

К этому времени в Беларуси сформировалась научная школа, центр которой базировался в НИИ прикладных физических проблем БГУ. Позже к этим исследованиям присоединились ученые кафедры органической химии Белорусского государственного технологического университета.

Следует отметить, что в настоящее время, несмотря на успехи, достигнутые в области синтеза жидкокристаллических соединений и создания на их основе разнообразных компози- 
ций, по-прежнему, несомненно, актуальной является разработка жидкокристаллических соединений, характеризующихся совокупностью оптимальных физико-химических параметров: невысокой температурой образования мезофаз и широким температурным интервалом их существования, малой вязкостью нематической фазы, высокими значениями положительной или отрицательной диэлектрической анизотропии; хорошо смешивающихся с жидкокристаллическими соединениями различных классов. Методы синтеза этих соединений должны характеризоваться доступностью исходных реагентов, отсутствием сложных технологических стадий, высоким выходом конечных продуктов.

Основная часть. Имея более чем 45-летний опыт исследований различных типов жидкокристаллических материалов, ученые Беларуси разработали оригинальные подходы к синтезу и созданию не только ЖК материалов для всех типов электрооптических устройств отображения информации, но и новых анизотропных материалов и устройств с широким спектром практического использования [1].

Предлагаемые схемы получения новых материалов и анизотропных веществ, моделирования различных процессов базируются на закономерностях эволюционного развития природных органических соединений; многочисленных данных, полученных в последние десятилетия при изучении жидких кристаллов и упорядоченных сред; использовании анизотропии молекул полифункциональных соединений для дизайна новых молекулярных структур (инженерия молекул), пленок, жидких кристаллов, мембран, мицелл и т. д., для создания анизотропных ансамблей молекул и биологических систем.

Так, в результате проведенных исследований для получения полярных жидких кристаллов были разработаны оригинальные методы синтеза, позволившие создать соединения с новыми сочетаниями используемых для этой цели структурных фрагментов и более высокими, по сравнению с известными мезогенами, значениями положительной или отрицательной диэлектрической анизотропии $[2,3]$. Общие формулы полученных новых ЖК с положительной (A) и отрицательной (Б) диэлектрической анизотропией указаны ниже (рис. 1).

Для синтеза анизотропных карбоциклических и гетероциклических соединений, имеющих стержнеобразную форму молекул и характеризующихся их ориентационной упорядоченностью, было предложено [4] использовать полифункциональные анизотропные соединения, такие как 3,6-дизамещенные циклогекс-2еноны (I), транс-2,5-дизамещенные циклогексаноны (II), 5-замещенные циклогексан-1,3дионы (III), 3,5-дизамещенные 2-изоксазолины $(\mathbf{I V}, \mathbf{V}), 1,2$-дизамещенные циклопропанолы (VI) и непредельные эпоксикетоны (VII) (рис. 2).

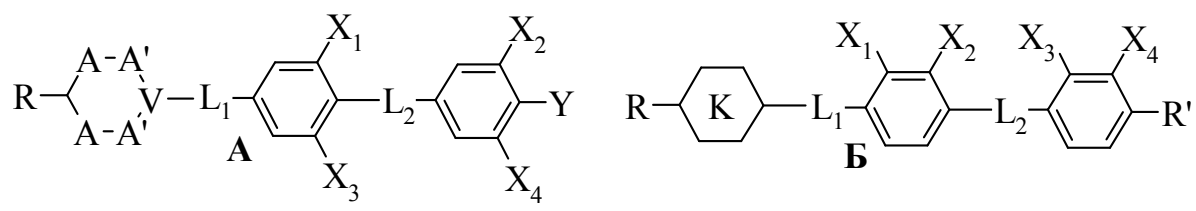

Рис. 1. Структурные формулы соединений с положительной (А) и отрицательной (Б) диэлектрической анизотропией:

A, A' - O, C; V-C, B, N; X $1-4-\mathrm{H}$ или F, Cl, $\mathrm{CF}_{3}, \mathrm{CH}_{3}$; Y - F или $\mathrm{Cl}, \mathrm{CN}, \mathrm{NCS}_{2} \mathrm{CF}_{3}, \mathrm{OCF}_{3}$; $\mathrm{K}$ - циклогексановое или бензольное кольцо; R, R' - алкильный или алкоксильный радикалы; $\mathrm{L}_{1-2}-$ связь или $\mathrm{CH}_{2} \mathrm{CH}_{2}, \mathrm{COO}$

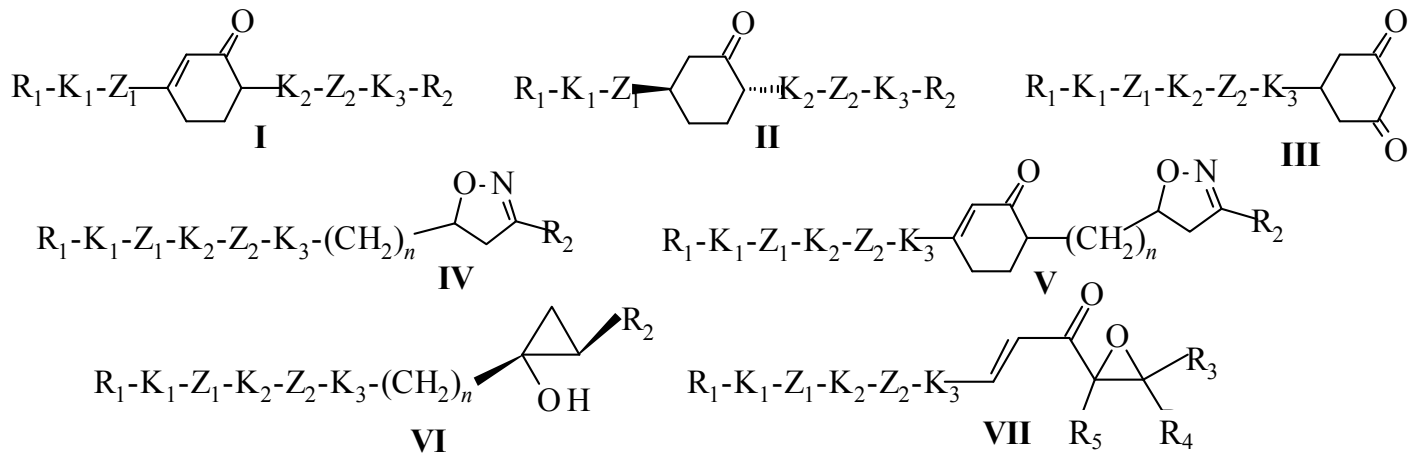

Рис. 2. Полифункциональные анизотропные соединения:

$\mathrm{R}_{1,2}$ - алкильный или алкоксильный радикалы, $\mathrm{F}, \mathrm{Cl}, \mathrm{CN}, \mathrm{CF}_{3}, \mathrm{OCF}_{3}$ или хиральный фрагмент; $\mathrm{K}_{1-3}-$ связь или бензольное, циклогексановое, циклогексеновое кольцо; $n-0-5$; $\mathrm{Z}_{1,2}$ - связь или $\mathrm{CH}_{2} \mathrm{CH}_{2}$, или другие мостиковые фрагменты; 1 - 0 или 1; $\mathrm{R}_{3-6}-\mathrm{H}$ или алкильный, арильный фрагменты 
Проведенный анализ синтетических методов получения замещенных циклогексенонов показал $[5,6]$, что для указанной цели наиболее перспективным является присоединение по Михаэлю замещенных винилкетонов к 2-замещенным ацетоуксусным эфирам, производным бензилметилкетона, ацетилацетона или аналогичным им дикарбонильным соединениям с последующей циклизацией без выделения в присутствии оснований промежуточных аддуктов присоединения [7, 8]. Данная методология синтеза указанных соединений характеризуется новизной подхода и позволяет получать с высоким выходом разнообразные циклогексеноны, из которых в зависимости от типа заместителей и их положения в циклических фрагментах, характера проводимых превращений может быть получен ряд анизотропных соединений, перспективных для практического использования в различных областях науки и техники. Изучение нами условий осуществления данных реакций показало, что 3,6-дизамещеные циклогекс-2-еноны (I) с различной комбинацией циклических, мостиковых, концевых и боковых заместителей образуются с 60-80\% выходом конденсацией соответствующих замещенных винилкетонов, солей Манниха или 2-хлор(бром)этил-арил(алкил) кетонов с 2-замещенными ацетоуксусными эфирами, 4-замещенными метилбензилкетонами, другими $\beta$-дикарбонильными соединениями в присутствии гидроокиси калия в кипящем диглиме или диоксане [9]. Последующее каталитическое гидрирование циклогекс-2-енонов (I) над 5\%-ным или $10 \%$-ным палладием на угле в присутствии гидроокиси калия в изопропаноле или смеси изопропанола и тетрагидрофурана позволяет получать соответствующие транс2,5-дизамещеные циклогексаноны (II) с выходом 70-80\% [10] (рис. 3).

Для синтеза 5-замещенных циклогексан-1,3дионов (III), как правило, также используют внутримолекулярную циклизацию аддуктов присоединения по Михаэлю, полученных при взаимодействии ацетоуксусного эфира или малонового эфира с $\beta$-замещенными акриловыми кислотами или их эфирами, с метил- $\beta$-замещенными этенилкетонами в присутствии алкоголятов щелочных металлов [11] (рис. 4)

Ключевой стадией синтеза 3,5-дизамещенных 2-изоксазолинов (IV, V), как показали исследования ученых ИБОХ НАНБ под руководствои академиков А. А. Ахрема и Ф. А. Лахвича, является реакция 1,3-диполярного циклоприсоединения нитрилоксидов, получаемых из соответствующих оксимов через стадию образования хлорангидридов гидроксамовых кислот, к соответствующим 1-алкенам, замещенным стиролам или другим ненасыщенным соединениям в присутствии $\mathrm{N}$-хлорсукцинимида и триэтиламина [12] (рис. 5).

Простой и эффективный способ получения замещенных циклопропанолов из сложных эфиров карбоновых кислот был разработан и досконально изучен белорусскими учеными под руководством профессора О. Г. Кулинковича. В результате проведенных исследований [13] было установлено, что 1-замещенные циклопропанолы образуются с высоким выходом (80-95\%) при добавлении соответствующих сложных эфиров к смеси 1 экв. изопропоксида титана (IV) и 3 экв. этилмагнийбромида. Было показано, что использование других реактивов Гриньяра и непредельных углеводоводов позволяет получать широкий ассортимент разнообразных 1,2-дизамещенных циклопропанолов (VI) (рис. 6), которые характеризуются большим синтетическим потенциалом.

Замещенные непредельные эпоксикетоны (VII) получали эпоксидированием замещенных 3-бутен-2-онов щелочной перекисью водорода и затем конденсацией замещенных метилоксиранилкетонов с соответствующими альдегидами (рис. 7) $[14,15]$ согласно методам, разработанным учеными кафедры органической химии БГУ под руководством профессоров И. Г. Тищенко, Л. С. Станишевского и продолженным профессором А. М. Звоноком.

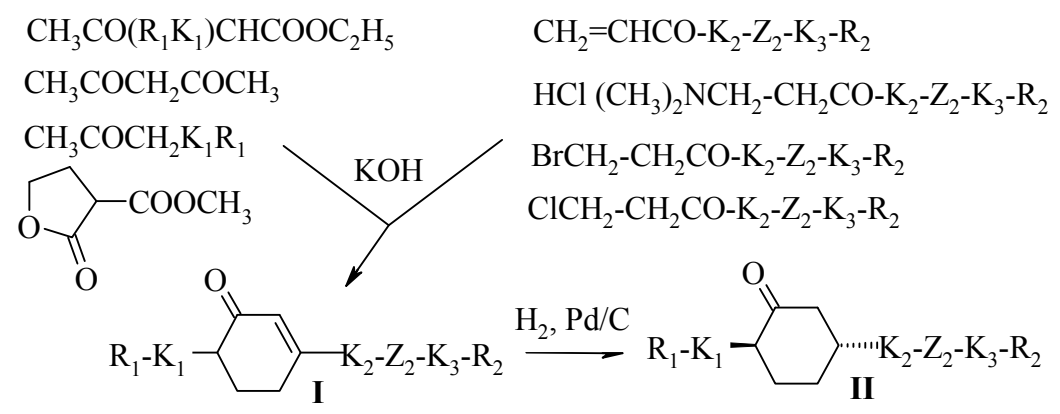

Рис. 3. Получение 3,6-дизамещеных циклогекс-2-енонов (I) и транс-2,5-дизамещеных циклогексанонов (II) 


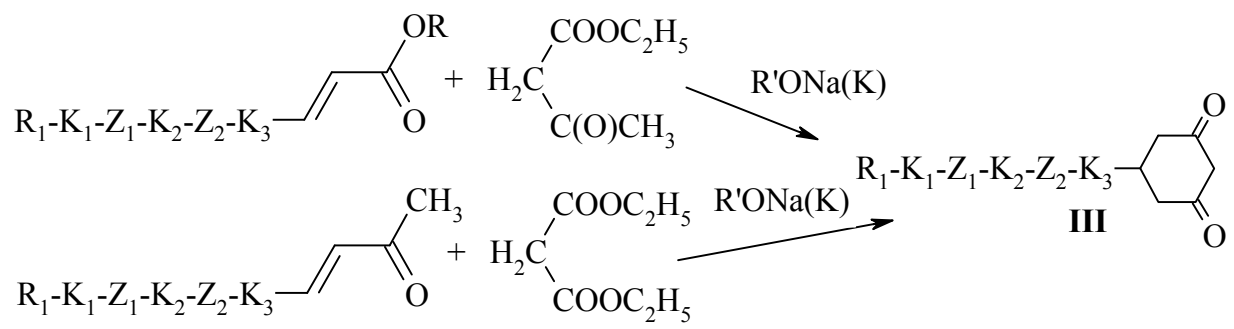

Рис. 4. Получение 5-замещенных циклогексан-1,3-дионов (III)

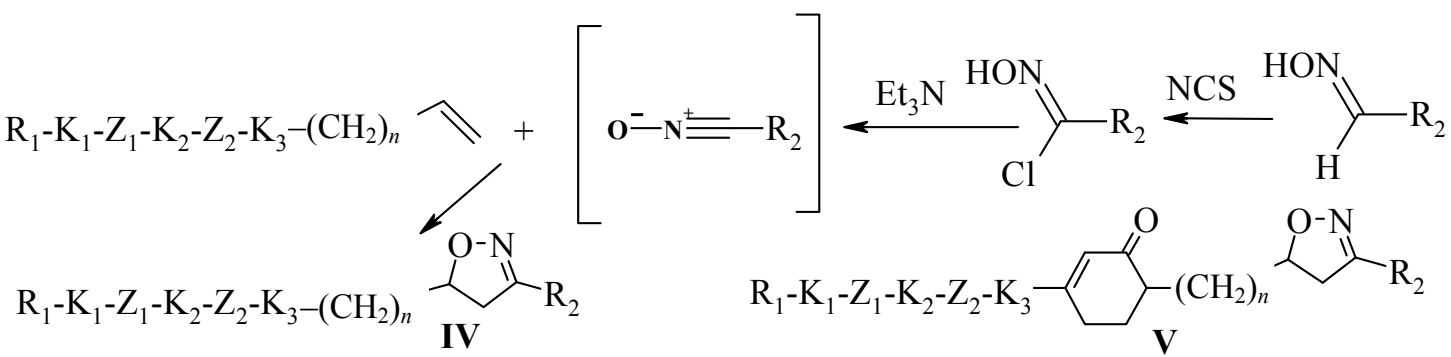

Рис. 5. Получение 2,5-дизамещеных 2-изоксазолинов (IV, V)

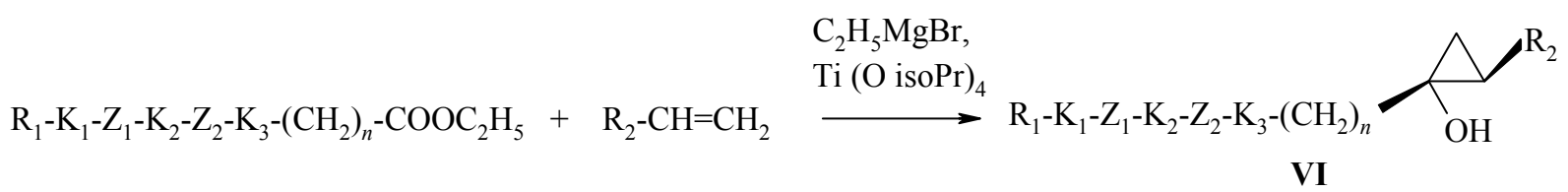

Рис. 6. Получение 1,2-дизамещенных циклопропанолов (VI)

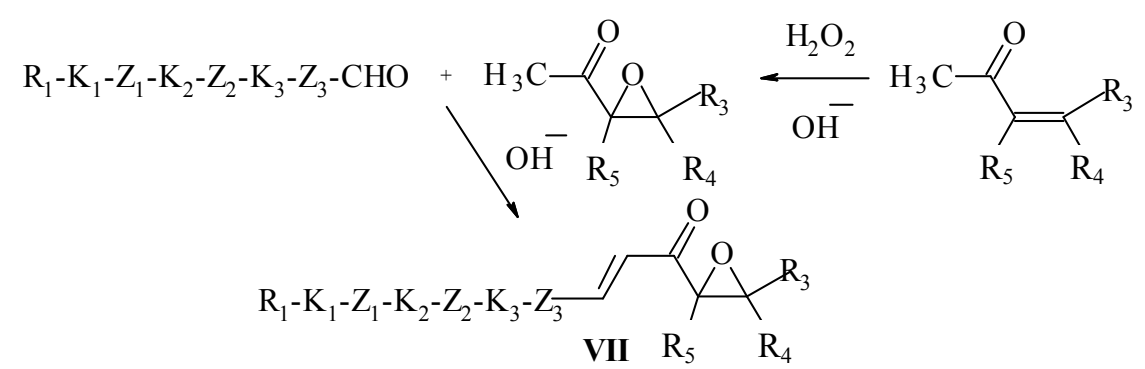

Рис. 7. Получение замещенных непредельных эпоксикетонов (VII)

В процесе проведенных исследований было установлено, что доступность и многообразие исходных реагентов, высокие выходы продуктов реакций, возможность модификации циклогексенонового, циклогексанонового, циклогександионового, изоксазолинового, циклопропанольного, эпоксикетонного фрагментов различными реагентами позволяют целенаправленно проводить синтез анизотропных материалов с желаемой комбинацией алкильных, циклических, мостиковых фрагментов, необходимым количеством и положением атомов галогенов, гидрокси-, других функциональных или полярных групп в центральной и концевой частях молекул.

Из методов, приводящих к модификации циклогексенонового фрагмента, особый интерес представляет его ароматизация, которая может протекать при высокой температуре на палладии на угле, при взаимодействии с $\mathrm{N}$-бром- сукцинимидом, йодом, а также под действием других реагентов [16] и позволяет получать разнообразные производные (1-6). Следует отметить, что в большинстве случаев процесс ароматизации, как правило, сопровождается появлением дополнительных заместителей в бензольном кольце (рис. 8).

Транс-2,5-дизамещенные циклогексаноны (II) также являются ценными полупродуктами синтеза разнообразных жидкокристаллических, анизотропных производных циклогексана и циклогексена с широким спектром практического использования.

Было установлено [17], что взаимодействие их с различными реагентами позволяет получать широкий ассортимент жидкокристаллических, анизотропных производных циклогексана и циклогексена (7-26) (рис. 9), перспективных для использования в различных областях науки и техники. 


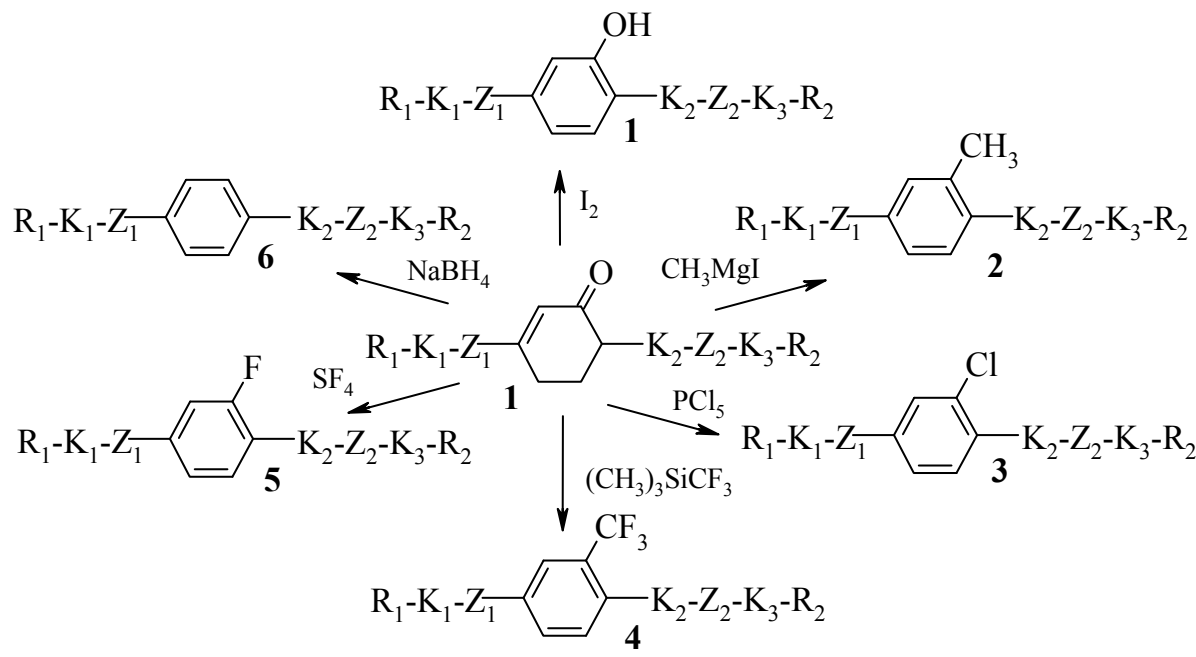

Рис. 8. Ароматизация 3,6-дизамещенных циклогекс-2-енонов:

$\mathrm{R}_{1,2}$ - алкильный или алкоксильный фрагменты, $\mathrm{F}, \mathrm{Cl}, \mathrm{CN}, \mathrm{CF}_{3}, \mathrm{OCF}_{3}$ или хиральный фрагмент; $\mathrm{K}_{1-3}$ - связь или бензольное, циклогексановое или циклогексеновое кольца;

$\mathrm{Z}_{1,2}$ - связь или $\mathrm{CH}_{2} \mathrm{CH}_{2}$, или другие мостиковые фрагменты;

Следует отметить, что из транс-2-алкил-5фенилциклогексанонов (27), также как и из транс-4-алканоил-1-фенилциклогексанов (30), могут быть получены, используя рассмотренные ранее реакции и превращения, 3,6дизамещенные циклогекс-2-еноны $(\mathbf{2 9}, \mathbf{3 2})$ [18], содержащие дополнительную кетогруппу в циклическом фрагменте или алкильном радикале (рис. 10). Различная реакционная способность кетогрупп, характерная для этих соединений, позволяет избирательно осуществлять их превращения и дает возможность получения новых анизотропных соединений с оригинальным сочетанием структурных фрагментов молекул и привлекательными свойствами.

Анизотропные 5-замещенные циклогексан1,3-дионы (III), также как и многие другие замещенные циклогексан-1,3-дионы, имеют несомненное прикладное значение, поскольку продукты их модификации (33-43) (рис. 11) характеризуются биологической активностью и широко используются для производства лекарственных препаратов, регуляторов роста растений и т. д. [11].

Следует отметить, что в настоящее время химия 2-ацилциклогексан-1,3-дионов (33) приобрела повышенное прикладное значение благодаря широкому применению ряда современных регуляторов роста растений, полученных на их основе, которые по структуре близки природным продуктам, характеризуются низкой токсичностью и отсутствием канцерогенных свойств. Несомненно актуальной является возможность использования различных 2-ацилциклогексан-1,3-дионов (циклических $\beta$-трикетонов) в качестве блок-синтонов натуральных продуктов и аналогов биологически ак- тивных гетеро- и карбоциклических соединений [11].

Что касается 3,5-дизамещенных 2-изоксазолинов (IV), замещенных циклогекс-2-енонил 2-изоксазолинов (V), то эти соединения перспективны для синтеза анизотропных соединений, различающихся структурными фрагментами в концевых частях молекул, таких как полициклические 1,3-аминоспирты (44), 1,3-диолы (45), $\beta$-оксикетоны (46), $\alpha, \beta$-непредельные кетоны (47) (рис. 12) [2].

Было установлено [2], что 1,3-диолы (45), $\beta$-гидроксикетоны (46) могут быть превращены в соответствующие фтор- и хлорпроизводные при взаимодействии с фтористоводородной, соляной кислотами, диэтиламинотрифторидом серы. $\beta$-Оксикетоны (46) могут также использоваться для получения соответствующих анизотропных металлокомплексов.

1,2-Дизамещенные циклопропанолы (VI) обладают богатым синтетическим потенциалом и могут вовлекаться в реакции с раскрытием цикла и образованием полезных для органического синтеза полифункциональных соединений. Наряду с методами получения $\beta$-галогенкетонов (49) или этилкетонов (50) через раскрытие трехуглеродного цикла гидроксициклпропанов (VI) по связи C1-C3 (рис. 13) были найдены способы их превращения в эпоксикетоны (51) через окислительное раскрытие цикла каталитическим окислением кислородом воздуха, 2-замещенные аллилбромиды (53) через индуцируемую $\mathrm{MgBr}_{2}$ катионную циклопропил-аллильную изомеризацию сульфонатов циклопропанолов, $\beta$-нитрозокетоны и соответствующие изоксазолы (52) с помощью алкилнитритов (рис. 13) [13]. 

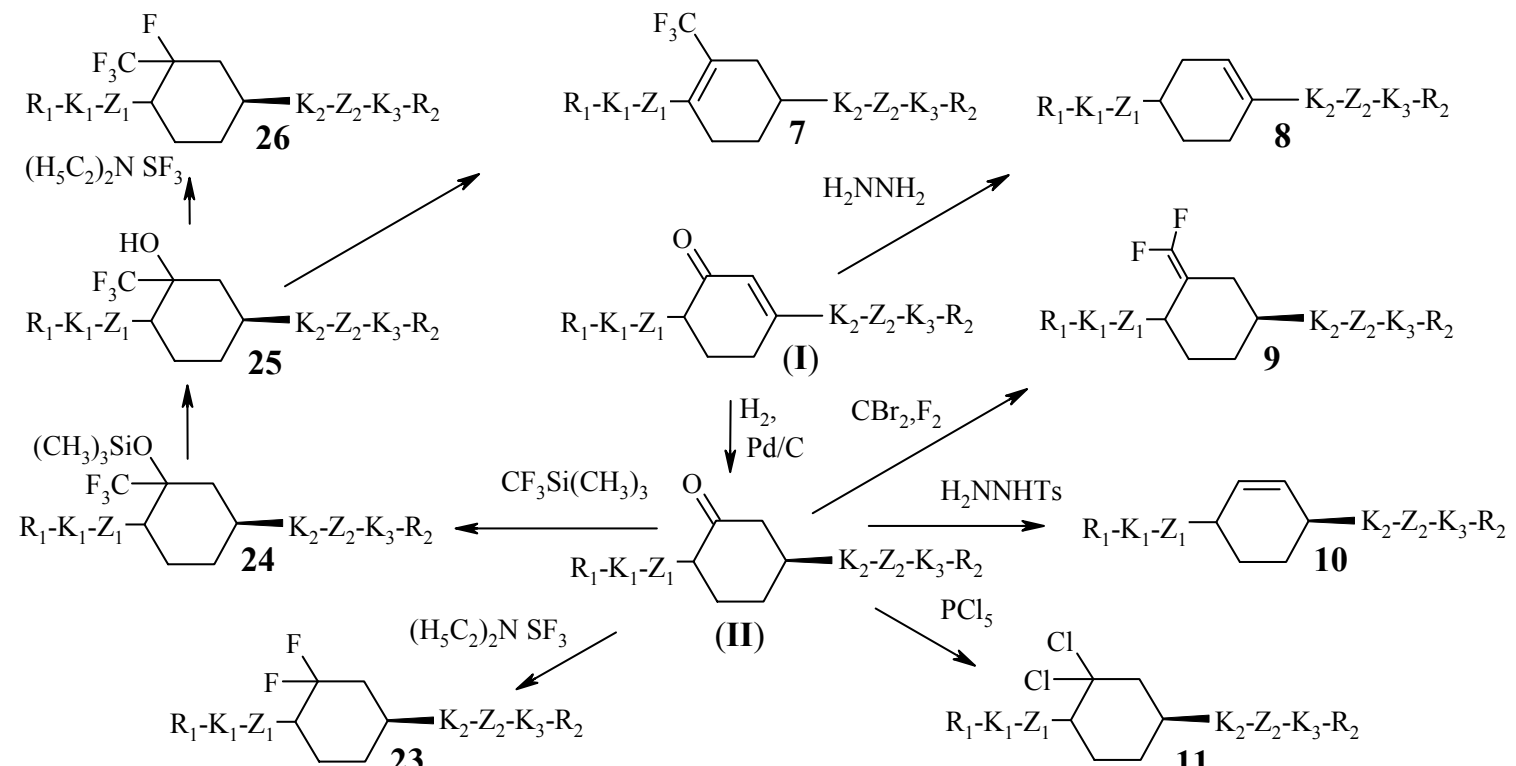

(II)
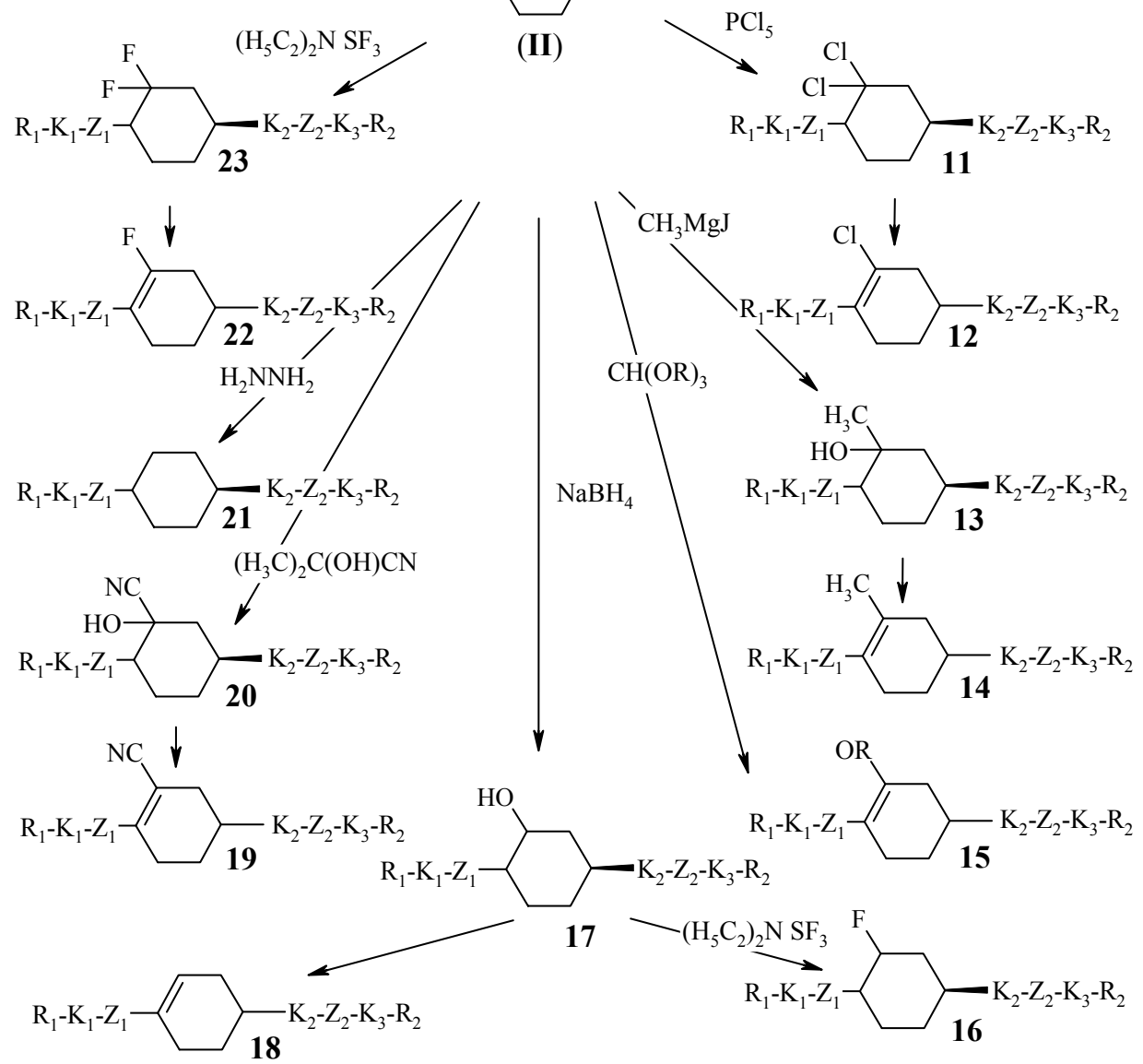

Рис. 9. Превращения транс-2,5-дизамещенных циклогексанонов:

$\mathrm{R}_{1,2}$ - алкильный или алкоксильный фрагменты, $\mathrm{F}, \mathrm{Cl}, \mathrm{CN}, \mathrm{CF}_{3}, \mathrm{OCF}_{3}$ или хиральный фрагмент;

$\mathrm{K}_{1-3}$ - связь или бензольное, циклогексановое или циклогексеновое кольца;

$\mathrm{Z}_{1,2}-$ связь или $\mathrm{CH}_{2} \mathrm{CH}_{2}$, или другие мостиковые фрагменты
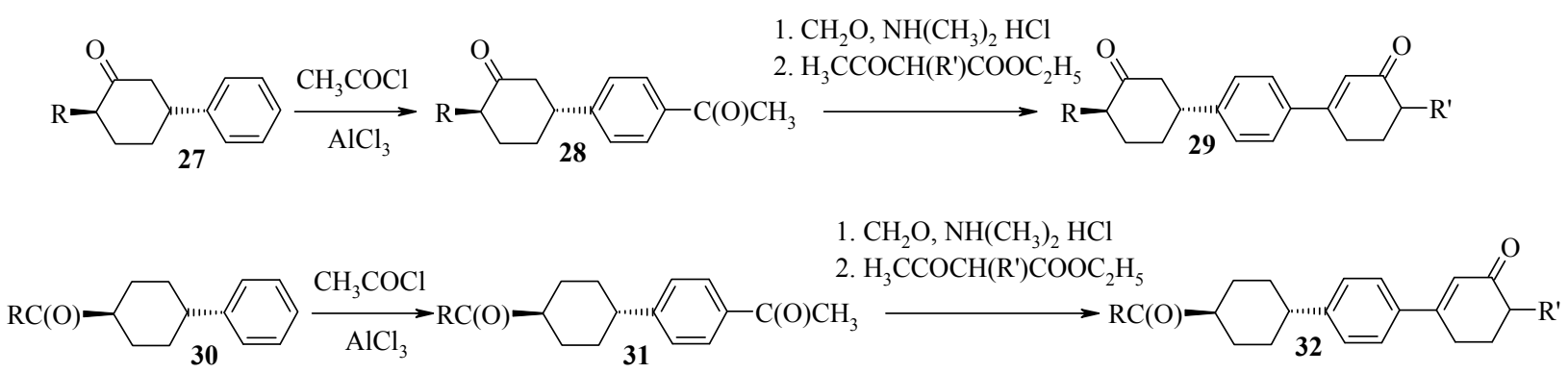

Рис. 10. Синтез 3,6-дизамещенных циклогекс-2-енонов $(\mathbf{2 9}, \mathbf{3 2})$ :

R, R' - алкильные радикалы 


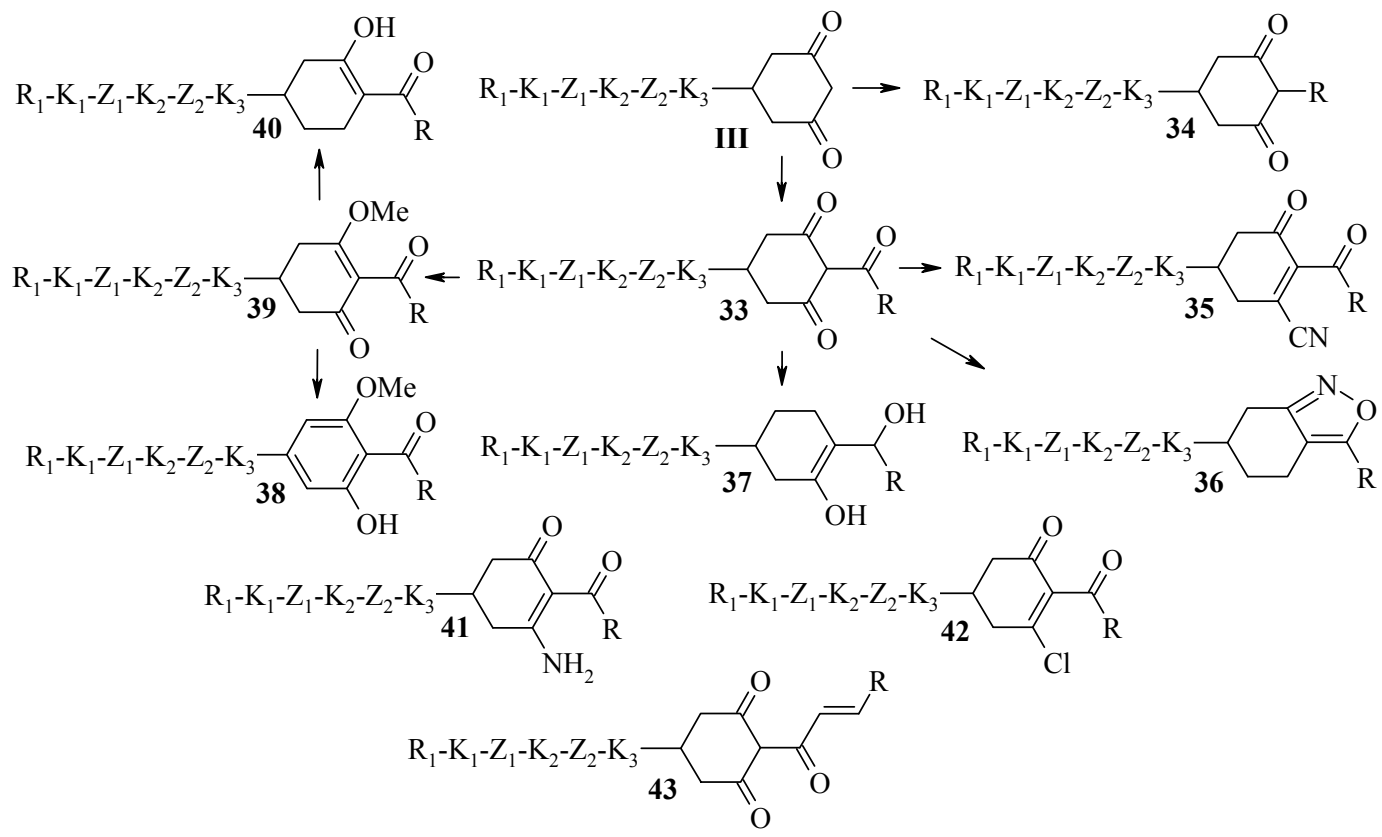

Рис. 11. Превращения 5-замещенных циклогексан-1,3-дионов (III)

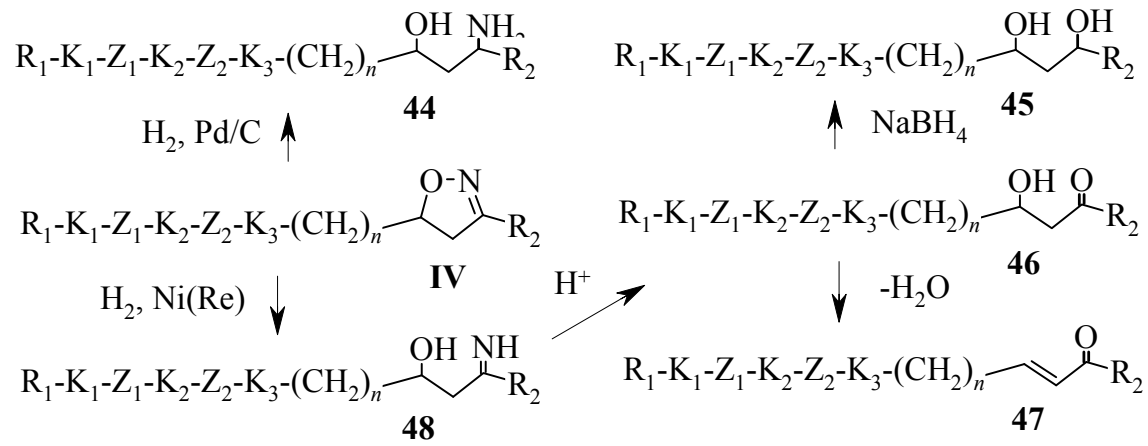

Рис. 12. Превращения 3,5-дизамещенных 2-изоксазолинов (IV)

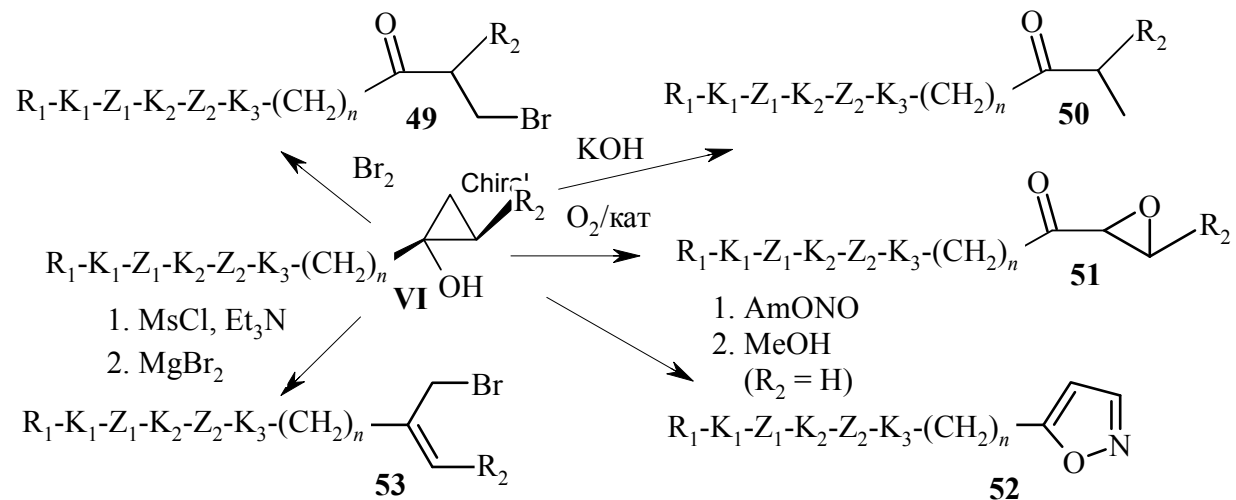

Рис. 13. Превращения 1,2-дизамещенных циклопропанолов (VI)

Непредельные эпоксикетоны (VII) также могут использоваться для получения аналогичных продуктов. Было установлено [19-20], что под действием воды, минеральных кислот или аминов происходит раскрытие эпоксидного цикла, сопровождающееся выделением соответствующих аминоспиртов (54) или водорастворимых солей (55), галогенгидринов (57) или $\alpha$-диолов (58), образующихся с высокими вы- ходами при взаимодействии аминоспиртов с кислотами (рис. 14). Кроме этого, кросссопряженные ненасыщенные эпоксикетоны (VII) могут вступать в 1,3-диполярное циклоприсоединение с диазосоединениями, нитрилоксидами или замещенными азидами, гидразинами. Это позволяет дополнительно генерировать ароматические и гетероциклы, вводить различные функциональные группы в $\alpha$ - или 
$\beta$-положения двойной связи (59-66) согласно превращениям, представленным на рис. 15,16 , получать анизотропные поверхностно модифицированные полимеры в результате образования связей между активированными центрами поверхностей и эпоксициклом ненасыщенных эпоксикетонов.

В результате проведенных исследований дополнительно было установлено [21], что вос- становление изоксазолинового фрагмента (IV, V), раскрытие циклопропанольного (VI) оксиранового (VII) циклов водой в кислой среде, галогенводородными кислотами, вторичными аминами открывают доступ к соответствующим $\alpha$-диолам, галогенгидринам или аминоспиртам, при этом последние могут быть переведены в водорастворимую форму в виде солей с минеральными кислотами.

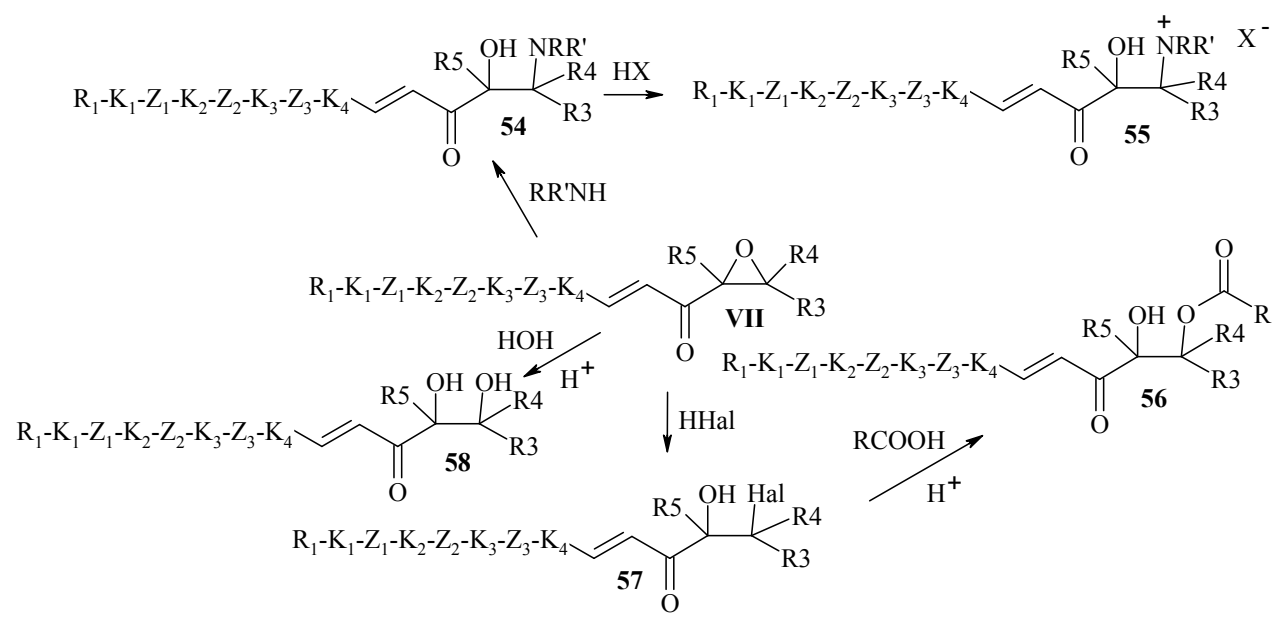

Рис. 14. Превращения эпоксикетонов (VII)

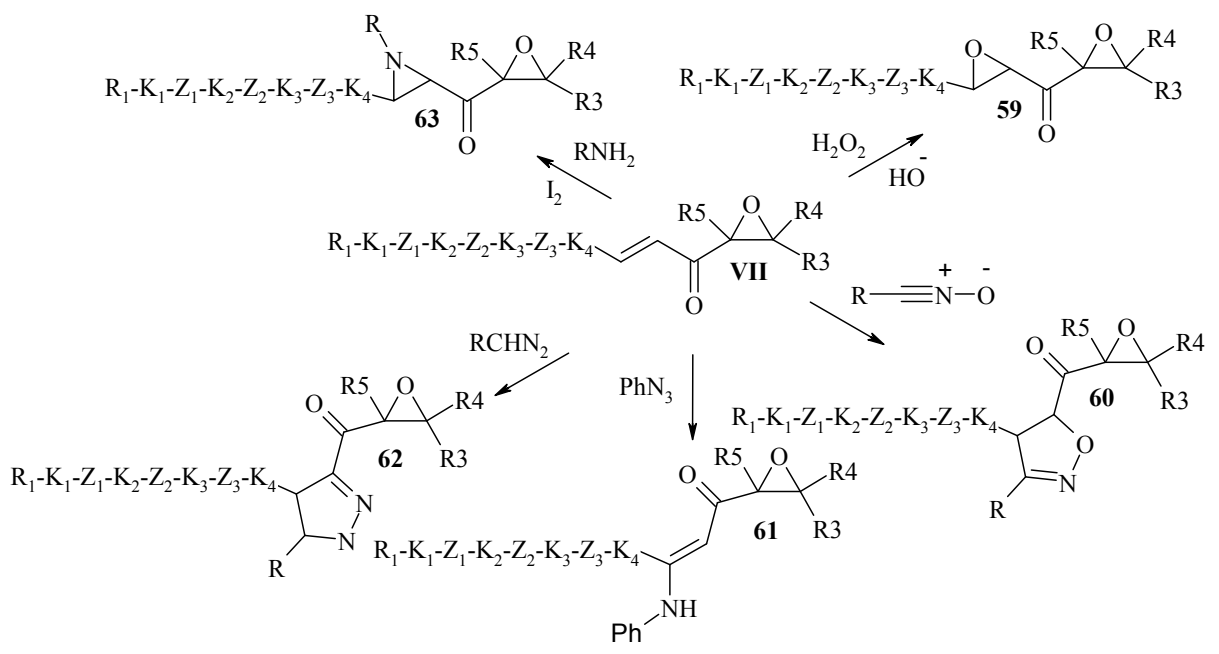

Рис. 15. Превращения эпоксикетонов (VII)

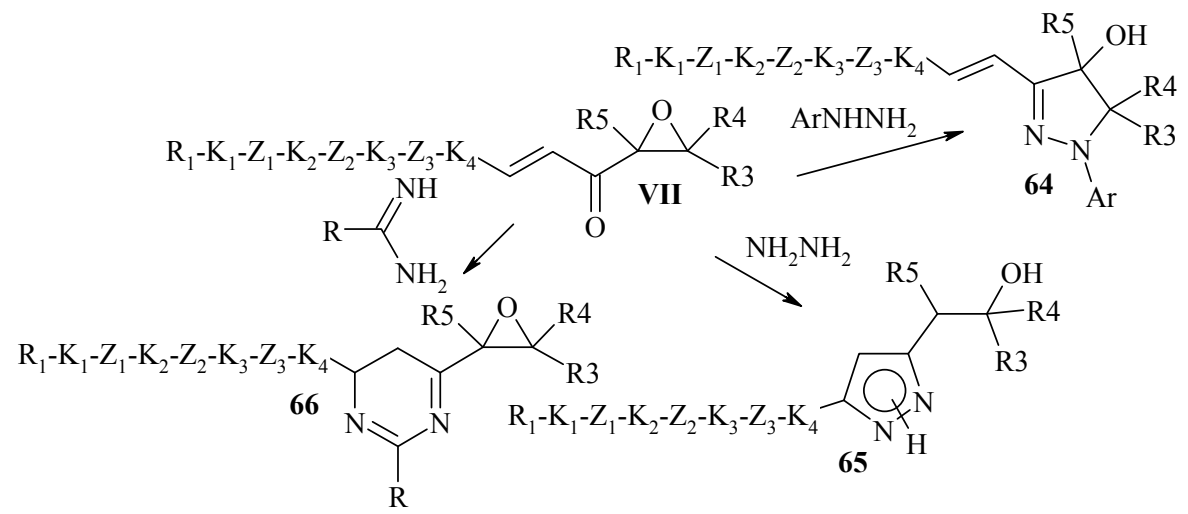

Рис. 16. Превращения эпоксикетонов (VII) 
Таким образом, как следует из приведенных результатов исследований, целенаправленный синтез 3,6-дизамещенных циклогекс-2-енонов (I), транс-2,5-дизамещенных циклогексанонов (II), 5-замещенных циклогексан-1,3-дионов (III), 3,5-дизамещенных 2-изоксазолинов (IV, V), 1,2-дизамещенных циклопропанолов (VI) и непредельных эпоксикетонов (VII), последующие их превращения открывают путь к получению новых анизотропных и жидкокристаллических материалов, перспективных для практического использования в различных областях науки и техники.

Результаты наших исследований также показали, что анизотропные свойства и хорошее упорядочение молекул природных полимеров дают возможность получения оригинальных высокоупорядоченных композитов с широким спектром практического использования путем включения биополимеров в синтетическую полимерную матрицу. Использование пептидных и углеводных строительных блоков в структуре сополимера позволило не только улучшать мезоморфное поведение и свойства, но и контролировать упорядочен- ность структуры и его биологическую функциональность.

Очевидно, что изучение анизотропных соединений, природных материалов, процессов самоорганизации в физико-химических системах, использование моделей биоэволюции являются основой развития современного материаловедения.

В этой связи возникла необходимость перейти от химии индивидуальных молекул к супрамолекулярной химии анизотропных соединений, а именно к новому направлению исследований - анизотропному материаловедению и детальному изучению процессов самоорганизации, лежащих в основе создания природных материалов и жизни на Земле.

Заключение. Несомненно, предлагаемая нами методология создания анизотропных веществ и материалов является креативной, имеет целый ряд отличительных достоинств, в сравнении с известными методами получения аналогичных структур, моделирования биологических систем, и с успехом может быть использована для создания новых поколений анизотропных материалов, не уступающих по свойствам природным.

\section{Список литературы}

1. Bezborodov V. S., Dabrowski R. Present and future of the liquid crystal chemistry // Mol. Cryst. Liq. Cryst. Sci. and Techn. 1997. Vol. 299 (1). P. 1-17.

2. Polyfunctional intermediates for the preparation of liquidcrystalline and anisotropic materials / V. S. Bezborodov [et al.] // Liquid Crystals. 2015. Vol. 42 (8). P. 1124-1138.

3. Bezborodov V. S., Lapanik V. I. Synthesis and mesomorphic properties of cyanoderivatives of 2-(4-carbohydroxy-3-halogenphenyl)-5-alkyl-1,3,2-dioxaborinanes // Liq. Cryst. 1991. Vol. 10. P. 803-807.

4. 3,6-Disubstituted cyclohexenones in the synthesis of new three ring liquid crystalline compounds with the negative dielectric anisotropy / G. Sasnouski [et al.] // Mol. Cryst. Liq. Cryst. 2011. Vol. 542 (1). P. 56-61.

5. Novello F. C., Christy M. E., Sprague J. M. Synthesis of substituted cyclohexenones // J. Am. Chem. Soc. 1953. Vol. 75 (6). P. 1330-1334.

6. Lauk U. H., Skrabal P., Zollinger H. Synthese und flussigkristalline tigenschaften 2,6-disubtituierter naphthaline // Helv. Chim. Acta. 1985. Vol. 68 (5). P. 1406-1426.

7. Sucrow W., Wolter H. Aliphatische flüssigkristalle, 3. Flussig-kristalline 2-cyclohexyldecaline // Chem. Ber. 1985. Vol. 118 (2). P. 3350-3356.

8. Sucrow W., Wolter H. Einige mesogene Tercyclohexylderivate // Chem. Ber. 1986. Vol. 119 (2). P. $387-400$.

9. Bezborodov V. S., Dabrowski R., Dziaduszek J. 3,6-Disubstitutedcyclohex-2-en-1-ones as intermediates for synthesis of liquid crystals with lateral substituted cyclohexane or benzene rings // Proceedings SPIE. 1994. Vol. 2372. P. 242-251.

10. A convenient method of synthesis of mesomorphic 2,5-disubstituted cyclohexan-1-ones by a catalytic reduction of 3,6-disubstituted cyclohex-2-en-1-ones / V. S. Bezborodov [et al.] // Liq. Cryst. 1996. Vol. 21 (2). P. 237-241.

11. Rubinov D. D., Rubiniva I. L., Akhrem A. A. Chemistry of 2-acylcycloalkane-1,3-diones // Chem Rev. 1999. Vol. 99. P. 1047-1065.

12. Koroleva E. V., Lakhvich F. A. Unusual transformations of 2-isoxazolines // Russ Chem Rev. 1997. Vol. 66. P. 27-42.

13. Kulinkovich O. G. The chemistry of cyclopropanols // Chem Rev. 2003. Vol. 103. P. 2597-2632.

14. Kuz'menok N. M., Koval'chuk T. A., Zvonok A. M. Synthesis of 5-hydroxy- and 5-amino-1-tosyl5-phenyl-3-(2-arylvinyl)-4,5-dihydropyrazoles // Synlett. 2005. No. 7. P. 485-486. 
15. Mikhalenok S. G., Kuz'menok N. M., Zvonok A. M. Redox transformation of adducts from cycloaddition of diazoacetic ester to $\beta$-arylacryloyloxiranes // Chem. Heter. Comp. 2005. Vol. 41. P. 977-986.

16. Synthesis and physical properties of liquid crystals having a chlorine atom in the lateral position of a benzene ring / V. S. Bezborodov [et al.] // Liq Cryst. 2006. Vol. 33. P. 1490-1496.

17. Bezborodov V. S., Petrov V. F. Liquid crystalline 1,4-disubstituted cyclo-hexenylene derivatives // Liq Cryst. 1999. Vol. 26. P. 271-280.

18. Bezborodov V. S., Lapanik V. I., Sasnouski G. M. LC diketones: synthesis, transformationas and mesomorphic properties // Liq Cryst. 2000. Vol. 27. P. 935-941.

19. Koval'chuk T. A., Kuz'menok N. M., Zvonok A. M. Reaction of 3-aryl-1-(2-methyloxiran-2-yl)prop-2-en-1-ones with tosylhydrazine // Chem. Heter. Comp. 2005. Vol. 41. P. 1237-1244.

20. Zvonok A. M., Kuz'menok N. M. Reaction of $\beta$-arylacryloxiranes with amidines // Chem. Heter. Comp. 1990. Vol. 26. P. 552-556.

21. Безбородов В. С. Химия жидкокристаллических материалов. Минск: БГТУ, 2017. 277 с.

\section{References}

1. Bezborodov V. S., Dabrowski R. Present and future of the liquid crystal chemistry. Mol. Cryst. Liq. Cryst. Sci. and Techn., 1997, vol. 299 (1), pp. 1-17.

2. Bezborodov V. S., Mikhalyonok S. G., Kuz'menok N. M., Lapanik V. I., Sasnouski G. M. Polyfunctional intermediates for the preparation of liquidcrystalline and anisotropic materials. Liq. Cryst., 2015, vol. 42 (8), pp. 1124-1138.

3. Bezborodov V. S., Lapanik V. I. Synthesis and mesomorphic properties of cyanoderivatives of 2-(4carbohydroxy-3-halogenphenyl)-5-alkyl-1,3,2-dioxaborinanes. Liq. Cryst., 1991, vol.10, pp. 803-807.

4. Sasnouski G., Bezborodov V., Dąbrowski R., Dziaduszek J. 3,6-Disubstituted cyclohexenones in the synthesis of new three ring liquid crystalline compounds with the negative dielectric anisotropy. Mol. Cryst. Liq. Cryst., 2011, vol. 542 (1), pp. 56-61.

5. Novello F. C., Christy M. E., Sprague J. M. Synthesis of substituted cyclohexenones. J. Am. Chem. Soc., 1953, vol. 75 (6), pp. 1330-1334.

6. Lauk U. H., Skrabal P., Zollinger H. Synthese und flussigkristalline eigenschaften 2,6-disubtituierter naphthaline. Helv. Chim. Acta, 1985, vol. 68 (5), pp. 1406-1426.

7. Sucrow W., Wolter H. Aliphatische flüssigkristalle, 3. Flussig-kristalline 2-cyclohexyldecaline. Chem. Ber., 1985, vol. 118 (2), pp. 3350-3356.

8. Sucrow W., Wolter H. Einige mesogene Tercyclohexylderivate. Chem. Ber., 1986, vol. 119 (2), pp. 387-400.

9. Bezborodov V. S., Dabrowski R., Dziaduszek J. 3,6-Disubstitutedcyclohex-2-en-1-ones as intermediates for synthesis of liquid crystals with lateral substituted cyclohexane or benzene rings. Proceedings SPIE, 1994, vol. 2372, pp. 242-251.

10. Bezborodov V., Dabrowski R., Sasnouski G., Dziaduszek J., Kohns P., Schirmer J. A convenient method of synthesis of mesomorphic 2,5-disubstituted cyclohexan-1-ones by a catalytic reduction of 3,6disubstituted cyclohex-2-en-1-ones. Liq. Cryst., 1996, vol. 21 (2), pp. 237-241.

11. Rubinov D. D., Rubiniva I. L., Akhrem A. A. Chemistry of 2-acylcycloalkane-1,3-diones. Chem. Rev., 1999, vol. 99, pp.1047-1065.

12. Koroleva E. V., Lakhvich F. A. Unusual transformations of 2-isoxazolines. Russ. Chem. Rev., 1997, vol. 66, pp. 27-42.

13. Kulinkovich O. G. The chemistry of cyclopropanols. Chem. Rev., 2003, vol. 103, pp. 2597-2632.

14. Kuz'menok, N. M., Koval'chuk T. A., Zvonok A. M. Synthesis of 5-hydroxy- and 5-amino-1tosyl-5-phenyl-3-(2-arylvinyl)-4,5-dihydropyrazoles. Synlett., 2005, no. 7, pp. 485-486.

15. Mikhalenok S. G., Kuz'menok N. M., Zvonok A. M. Redox transformation of adducts from cycloaddition of diazoacetic ester to $\beta$-arylacryloyloxiranes. Chem. Heter. Comp., 2005, vol. 41, pp. 977-986.

16. Bezborodov V., Dąbrowski R., Dziaduszek J., Czupryński K., Raszewski Z. Synthesis and physical properties of liquid crystals having a chlorine atom in the lateral position of a benzene ring. Liq. Cryst., 2006, vol. 33, pp. 1490-1496.

17. Bezborodov V. S., Petrov V. F. Liquid crystalline 1,4-disubstituted cyclo-hexenylene derivatives. Liq. Cryst., 1999, vol. 26, pp. 271-280.

18. Bezborodov V. S., Lapanik V. I., Sasnouski G. M. LC diketones: synthesis, transformationas and mesomorphic properties. Liq Cryst., 2000, vol. 27, pp. 935-941.

19. Koval'chuk T. A., Kuz'menok N. M., Zvonok A. M. Reaction of 3-aryl-1-(2-methyloxiran-2yl)prop-2-en-1-ones with tosylhydrazine. Chem. Heter. Comp., 2005, vol. 41, pp. 1237-1244. 
20. Zvonok A. M., Kuz'menok N. M. Reaction of $\beta$-arylacryloxiranes with amidines. Chem. Heter. Comp., 1990, vol. 26, pp. 552-556.

21. Bezborodov V. S. Khimiya zhidkokristallicheskikh materialov [Chemistry of liquidcrystalline materials]. Minsk, BGTU Publ., 277 p.

\section{Информация об авторе}

Безбородов Владимир Степанович - доктор химических наук, профессор кафедры органической химии. Белорусский государственный технологический университет (220006, г. Минск, ул. Свердлова, 13a, Республика Беларусь). E-mail: v_bezborodov@yahoo.com

\section{Information about the author}

Bezborodov Vladimir Stepanovich - DSc (Chemistry), Professor of the Department of Organic Chemistry. Belarusian State Technological University (13a, Sverdlova str., 220006, Minsk, Republic of Belarus). E-mail: v_bezborodov@yahoo.com. 